ZRC SAZU, Ljubljana

silvot@zrc-sazu.si

\title{
O NAJBARDZIEJ TYPOWYCH ZMIANACH MORFEMICZNYCH I FONOLOGICZNO-FONETYCZNYCH W TOPONIMII SŁOWEŃSKIEJ
}

Słowa tematyczne: zmiany morfemiczne, zmiany fonologiczno-fonetyczne, toponimia słoweńska, etymologia słoweńskich nazw geograficznych

Przedmiotem artykułu są wybrane zmiany morfemiczne (I) i fonologiczno-fonetyczne (II) w toponimii słoweńskiej ${ }^{1}$. Rozpatrujemy przede wszystkim te nazwy, które dotychczas nie były objaśniane albo zostały objaśnione nieprzekonująco².

Formą wyjściową w hasłach jest nazwa współczesna, zawarta w opracowaniach materiałowo-normatywnych Stoweńskie nazwy miejscowe (SKI 1985) oraz Stoweńskie nazwy miejscowe w Karyntii austriackiej (Zdovc 1993). Zawierają one także nazwy mieszkańców i przymiotniki derywowane od nazw miejscowych, w tym formy dialektalne. Zapisy historyczne zostały zaczerpnięte ze źródeł i opracowań wydanych przez historyków (Kos 1975; Blaznik 1986-89; Jožefinski zemljevidi 1995-2001). Dokładna obserwacja rozwoju nazw miejscowych nasuwa niekiedy nowe rozwiązania etymologiczne.

\section{ZMIANY MORFEMICZNE}

1. Wymiana sufiksów ekwiwalentnych ${ }^{3}$ $-(o v) i c a \rightarrow-(o v) i k \rightarrow-(o v) k a:$

Gábrovka: *Gabrovik (1279 Gabrovik, 1843 Gabrovk) $\rightarrow$ Gabrovka (1894 Gabrovka) (< psł. *grabrb 'grab'); (1982).

${ }^{1}$ Inspiracją do podjęcia niniejszego tematu była książka polskiego językoznawcy A. Bańkowskiego

${ }^{2}$ Najlepszym dotychczas opracowaniem toponimii słoweńskiej jest praca M. Snoja (2009), zawierająca 1650 artykułów słownikowych, w których objaśniono ok. 4 tys. słoweńskich toponimów. Książka krytycznie streszcza dociekania poprzednich pokoleń językoznawców słoweńskich i obcych oraz uzupełnia je wynikami badań autora.

${ }^{3}$ Problematyka ta wyczerpująco została przedstawiona w: Torkar 2012b: 147-148. 
Hrúševka: *Hruševica (1436 Chrusewicz) $\rightarrow$ *Hruševik $(1780$ Hruschouk $) \rightarrow$ Hruševka (1826 Hruschouka) (< psł. *gruša, *kruša 'grusza');

Žerjávka: *Žerjavica (1436 Seryawicz) $\rightarrow$ *Žerjavik (1780 Schereauk) $\rightarrow$ Žerjavka (1826 Scherjauka, 1894 Žerjavka) (< psł. *žerav-jb ‘żuraw').

-ina $\rightarrow-$ nik $\rightarrow$-inal-bj-:

Rakitna: *Rakitina $(1265$ Raquitina $) \rightarrow *$ Rakitnik $(1463$ Rakitnik $) \rightarrow *$ Rakitina (1689 Urakitene) (< psł. *orkyta 'wierzba rokita');

Svétina, dial. Svétje: *Svetina (1421 Swettein, 1524 Schwettina $) \rightarrow$ *Svetnik $(1582$ Suetnig) $\rightarrow$ *Svetina $(1621$ Suetina, 1780 Svetina $)(<$ psł. n. os. *Svętъ) (Snoj 2009: 403).

$-j b \rightarrow-b n:$

Ljúbno, dial. Lúbən: *Ljubelj (1358 Lewfel, 1498 Levfel) $\rightarrow{ }^{*}$ Ljubno (1581 Leiben, 1689 Lubno, 1823 Ljubno) (< psł. n. os. *L'ubb) (Torkar 2008: 25).

2. Uniwerbizacja

a) przez sufiksację substantywizującą:

hydr. Dóbršnik $\leftarrow{ }^{*}$ Dobrušnik $\leftarrow{ }^{*}$ Dobrušni potok (1073 in rivo Tobropotoch quod teutonico Guotpach) $(<$ psł. *Dobrušbnъ(jb) potokъ < n. os. *Dobrušb);

Jéprca $(<*$ Veprica $) \leftarrow$ *Vepra gorica $(1689$ Eperg $<*$ Eberberg $)(<$ psł. *vepra gorica 'wieprzy pagórek'); o zmianie fonetycznej $v>j$ zob. niżej (pkt 9);

Knežák $\leftarrow$ *Knežji studenec (1431 Knesok, 1498 Grauen Prunn, 1780 Kneshak oder Graffenbrunn) (< psł. *kъnęgъ 'książę');

Martinják $\leftarrow{ }^{*}$ Martinj potok $(1377$ Merteinspach, 1581 Martin potoc $)(<\mathrm{n}$. os. Martin);

Sínja Gorica $\rightarrow$ *Svinnica (1689 Suinize) (< psł. *svinbna gorica 'świński pagórek');

Stŕme Njive $\rightarrow$ *Strmica (1526 Stermytz) ( $<$ psł. *strbma niva 'stroma niwa');

b) przez substantywizację wyrażeń przyimkowych:

oron. Méngore $\leftarrow$ *Med gore (1523 Zwischen pirg genant in windisch Namengorach) (< psł. *medb gory 'między góry') (Torkar 2014: 114);

Néverke $\leftarrow$ *Med vrhe (1460 Meduerkch) (< psł. *med v vbrhy 'między szczyty') (Torkar 2009c: 379);

c) przez elipsę:

Jelénje $\leftarrow$ *Jelenje polje (1419 Hirsveld, 1744 Jelleine $)(<$ psł. *elen-je pol'e 'jelenie pole');

Studéno $\leftarrow$ *Studeno polje (1162 Kaltenfeld $)(<$ psł. *studeno pol'e 'zimne pole');

Vévče $\leftarrow$ *Belče polje $(1653$ na Belzhem, ys Belzhiga $)(<$ psł. *Bělbc-je pol'e $)<$ n. os. *Bělbcb (Torkar 2009b: 83);

d) przez przekształcenie w zrost albo złożenie:

Béžigrad ('gród, zamek, do którego się ucieka', od bežati 'uciekać' + grad) (Torkar 2011: 354). Inne przykłady tego typu złożeń w toponimii południowosło- 
wiańskiej: Skočidol, Bežidolina, Skočiles, niem. Atschalas (w Słowenii i w Karyntii austriackiej), Skočigrm (w Hercegowinie), Скочивир (w Macedonii), Pazdigrad $\left(<*_{p b z d i-}\right)$ (w Chorwacji);

Zanígrad $\leftarrow *$ Zvonígrad (1251 Xuonigrat, 1579 in villa Suanegrad) $(<$ psł. *zvbnigords 'gród, zamek, który dzwoni, dźwięczy, brzmi’, ‘brzmiący gród', od zvoniti + grad; słowo grad mogło oznaczać miejsce zagrodzone, twierdzę, kościół albo nawet jaskinię, która brzmi, dźwięczy, por. Zvónigrad, speleonim na pogórzu Velebit w Chorwacji, pol. Żmigród (1155 Zunigrod, czyli Zwnigrod) i ros. Звенигород (Skok 1973: 668; Malec 2003: 280; Torkar 2017: 336). Nieuwzględnienie onomastycznego materiału południowosłowiańskiego przy etymologizacji tej ogólnosłowiańskiej nazwy może prowadzić do błędnych wniosków (Šilov 2009: 99).

\section{Fałszywa dekompozycja}

Ánhovo $\leftarrow$ *Vanihovo (1330 Wanichove) (< n. os. *Vanih) (Snoj 2009: 46). Forma Anhovo powstała w wyniku odrzucenia nagłosowego $v$-.

Ávče (dial. Avč) $\leftarrow{ }^{*}$ Davč $(<$ psł. *Dalbc-jb bergъ < n. os. *Dalbcb, por. stp. n. os. Dalec) (Torkar 2016b: 207). Forma $A v c ̌$ (dial.) powstała w wyniku reinterpretacji (resegmentacji) nazwy przyimkowej *na Davč w *nad Avč.

\section{Derywacja fleksyjna}

Dôvje $\leftarrow$ *Dolgo polje (por. miejscownik dial. na Dovjem = na Dolgem, 1029-1045 Lenginvuelt, 1689 Nadougem) (< psł. *dblgoje pol'e) (Ramovš 1924: 38). Badacze słoweńscy objaśniali dotychczas formę Dovje jako przykład nietypowej słoweńskiej kontrakcji pełnej formy przymiotnika: *Dolge polje $<*$ Drlgoje pol'e (Snoj 2009: 120). W ten sam sposób objaśniali także toponim Dobrépolje, Velesovo i dial. Morskje. Naszym zdaniem formy te powstały najprawdopodobniej na drodze derywacji fleksyjnej z form miejscownikowych na Dovjem (dial. dla na Dolgem, mian. *Dolgo), *v Dobrém polju (mian. *Dobrópolje), *v Velém selu (mian. *Velóselo), v Morském (mian. *Mórsko).

Jereslávec $\longleftarrow$ dop. od *Jereslavci $(1780$ Jeroszlavcze) $(<$ n. os. *Jaroslavb).

Mokrónog $\leftarrow$ dop. od *Mokronoge (1143-47 Nazzenfuz) (zbiorowe przezwisko mieszkańców) (Torkar 2009a: 415).

Žálec $\leftarrow$ dop. od *Žalci $(1654$ Vshauzah) (n. mieszk. wsi *Žalina) (Torkar 2009a: 415).

5. Skrócenie sufiksu -jane $>$-je

Boróvlje $\longleftarrow$ *Boróvljane (<psł. *borz 'sosna').

Dólje $\longleftarrow *$ Dóljane (1525 Dolian) (< psł. *dolъ ‘dół; dolina’).

Ždóvlje $\leftarrow *$ Židovljane $(1246$ Sidolach) $(<* Z ̌ i d b$, por. czas. *žbdati) (Scheinig 1905: 6). 
6. Hybrydyzacja nazw

Jágnjed (wł. Iainich) $\leftarrow$ *Jamnik $(1220$ Jamnich $)(<*$ jamni les $<$ psł. *jama + friulski suf. -ed < łac. -etum) (Torkar 2012c: 695).

Prosníd (wł. Prossenicco) $\leftarrow *$ Prosenik $(<$ prosen < psł. *proso + friulski suf. -ed < łac. -etum) (Frau 1978: 114; Torkar 2012c: 695). Sufiks słoweński -ik substytowany był friulskim -ed; inaczej: M. Snoj (2009: 335); $165)$.

Vižinga (niem. Visingen) $\leftarrow$ *Vyšynje (pol'e) $(<$ n. os. *Vyšb) (Torkar 2015c:

7. Singularyzacja i pluralizacja

Košana $\leftarrow$ *Košane (1689 Kassane, n. mieszk. na -jane) (< psł. *koša 'sianokosy’) (Torkar 2007a: 487; Snoj 2009: 204).

Kozmerice $\leftarrow{ }^{*}$ Gostomerica $\left(1377\right.$ Costameriça) $\left(<\mathrm{n}\right.$. os. ${ }^{*}$ Gostimirr $)($ Košmrlj 1970: 107).

Hrénovice $\longleftarrow$ *Hrenovica $(1272$ Crenoviç) (< psł. *hrěns 'chrzan').

Ljubljana $\leftarrow$ *Ljubljane (1146 Luwigana, n. mieszk. na -jane do hydr. Ljubija) (< n. os. *L'ubovidb) (Torkar 2007a: 267). Najprawdopodobniej pierwotną nazwą rzeki Ljubljanicy była Ljubija (dzisiaj tę nazwę nosi jedno z trzech źródeł Ljubljanicy), forma posesywna z suf. -ja od n. os. * Ljubid (<* L’ubovidb), por. pol. top. Libidza. Liczne nazwy na -jane już wcześnie przeszły singularyzację na bazie przemiany fonetycznej -jane $>$-jana.

8. Deminutywizacja

Modréjce $\leftarrow$ *Modréje (1321 Modreçe) (<n. os. *Modrějb) (Torkar 2010a: 133). Obok toponimu Modrejce z sufiksem -ica w lm. istnieje nazwa Módrej, która powstała z formy *Modreje w wyniku singularyzacji (obiekty zlokalizowane są blisko siebie).

Telčice $\leftarrow$ Telče $(1433$ Teltschicz) $(<\mathrm{n}$. os. Telbcb) (Bezlaj 1956: 255). Miejscowości Telče i Telčice znajdują się w sąsiedztwie.

\section{ZMIANY FONOLOGICZNO-FONETYCZNE}

\section{Metateza}

Cánkova $\leftarrow$ *Stankova $(1784$ Kaltenbrun oder Szankowcze $)(<$ n. os. *Stanbko $)$. Wcześniej wywodzono ten top. od niem. n. os. Zank (Snoj 2009: 87).

Snéberje $\leftarrow *$ Sebemirje (1359 Zzomebryach, 1363 Sewemriach) $(<\mathrm{n}$. os. *Seběmirb) (Torkar 2015b: 108). F. Bezlaj (1977: 226; 1995: 279) wywodził top. Sneberje z bezprzyimkowego miejscownika *siń(ej)ems vyrbjě ( *sińbjo vyrbjb 'siny wir') i porównywał go z macedońskim top. Синевир. 


\section{A fereza}

Mágozd $\leftarrow *$ Domagost $(1570$ Domagost) $(<\mathrm{n}$. os. *Domagostb) (Torkar 2012c: 696). Wcześniej wywodzono ten top. z zestawienia *mali gozd 'mały las' (Čop 2007: 119; Snoj 2009: 87).

Modráže $\leftarrow$ *Ninodraže $(1490$ Nysodras, 1822 Minotrasch $)(<$ n. os. *Ninodragz $)$ (Torkar 2011: 73).

oron. Tóšč $\leftarrow$ *Ljutošec (1589 Lotafchiz) (< n. os. *L’utošb) (Bezlaj 1956: $345)$.

\section{Synkopa}

Jázne $\longleftarrow$ *Jazbine (1523 Jassbina) (< psł. *ězvina 'nora borsuka').

Ráćje selo $\leftarrow *$ Radeče selo (1689 Naradezheselu) $(<\mathrm{n}$. os. *Radęta) (Pintar 1912: 553).

\section{Asymilacja i dysymilacja}

Andól $\leftarrow{ }^{*}$ Landol (< psł. *olni), por. pol. top. Eania (Torkar 2009b: 78). W dotychczasowych słoweńskich gramatykach historycznych nazwę tę objaśniano jako refleks psł. *odolb, por. pol. ap. Wadół.

oron. Gólovec $\longleftarrow *$ Volovec (XVI-XVIII w. Volouz) $(<\mathrm{n}$. os. *Volb $<*$ Volimirz) (Torkar 2015a: 281). Stare zapisy odzwierciedlają pierwotną postać nazwy przed dysymilacją $v-v>g-v$.

Míren $\leftarrow$ *Niren (< psł. *nyrbnb) (Torkar 2010b: 823). Wieś Miren znajduje się koło rzeki Wipawy, w miejscu, gdzie część rzeki znika i płynie dalej pod ziemią. Wcześniej wiązano nazwę z ap. mir (< łac. murus) (Snoj 2009: 263).

Prédoslje $\leftarrow *$ *Preraslje (1304 Prerazel) (< psł. *per-orslb), por. pol. Przerośl, ukr. Перерісль, serb. Прераст і Пераст (Bezlaj 1967: 6; Snoj 2009: 328; Torkar 2012a: 320). Bezlaj wywodził top. Prédoslje od domniemanego ap. *prěroslo, nie przytaczając słowiańskiego materiału porównawczego. W literaturze serbskiej top. Пepacm zwykle wiąże się z nazwą iliryjskiego plemienia Pirustae (Aleksandar Loma, e-mail z 20 września 2012 r.).

5. Redukcja samogłoskowa oron. Krim $\leftarrow *$ Kurim (1689 Khorim, 1726 Kurin) (< psł. *kurims (vbrh ) `dymiący (szczyt)') (Torkar 2007b: 252). Por. czes. top. Kouřim i Kuřim.

6. Zanik spółgłosek wybuchowych oron. Pórezen $\leftarrow$ *Podresen (1654 Vporssnimb) (< psł. *podb versbnb) (Torkar 2003: 436), por. pol. top. Września.

Sódražica $\leftarrow$ *Stojdražica (1220 Stoidrasicz) $(<$ n. os. *Stojbdragz) (Bezlaj 1961: 204). 
7. Udźwięcznienie

Radmirje $\leftarrow$ *Bratimirje (1426 Fretmansdorf Wratymyeri) $(<$ n. os. *Bratimirb) (Torkar 2013: 117).

Vižmarje $\leftarrow$ *Višemirje (1421 Geysmerstorf) $(<\mathrm{n}$. os. *Vyšemirz), por. pol. Wyśmierzyce (Torkar 2015c: 164). Wcześniej wywodzono ten top. od niem. n. os. Gismar (Snoj 2009: 461).

8. Lenicja i zanik spółgłosek zwartych

Pržánj $\longleftarrow *$ *Prežganje (1823 Preshgain, dop. Preshgaina, 1826 Persain) $(<$ czas. žgati 'prażyć') (Torkar 2011: 357).

9. Specyficzne zmiany fonetyczne

oron. Blégoš $\longleftarrow$ *Blagoš (n. os. *Blagošb) (Torkar 2010a: 247). Nazwę tę wywodzono wcześniej od niem. oron. Flöherskofel (Bezlaj 1976: 26; Kranzmayer, Lessiak 1983: 63; Snoj 2009: 65). Nie brano pod uwage rzadkiej dialektalnej zmiany fonetycznej $a>e$, por. także plámen $>$ dial. plémen, kákat $>$ dial. kékat $\mathrm{i}$ in

Borje (< *Dvorjane, 1392 Wari, 1468 Bory, 1496 Tworiach) (< psł. *dvorb, dial. dbor $>$ bor $)$;

Cvetkóvci $\leftarrow$ *Svetohovci $(1413$ Zwetochawczen $)(<\mathrm{n}$. os. *Svętohъ) (Torkar 2010a: 50).

Gorjánsko $\leftarrow$ *Dvorjansko (1308 de Voriansco) (< psł. *dvorb przez dial. dgor > gor) (Torkar 2015a: 98). Wcześniej wywodzono ten toponim od n. mieszk. *Gorjane $(<$ ap. gora), ponieważ nie brano pod uwagę zmiany fonetycznej $d v>d g$, a także $v>g$.

Jéprca $(<*$ Veprica $) \leftarrow *$ Vepra gorica $(1689$ Eperg $<*$ Eberberg $)(<$ psł. *vepra gorica). Wcześniej wywodzono ten top. od niem. ap. Herberge 'nocleg; miejsce noclegu' (Ramovš 1924: 81; Snoj 2009: 177). Zmiana $v>j$ nie została zauważona dotychczas w słoweńskim rozwoju fonetycznym, a większość przypadków poświadczona jest w nazwach własnych, np. Jéperjek < *Veprjane (1425 Wepriach), Jénkovo < *Venkovo (1256 Vincou) (Torkar 2017: 335).

10. Transpozycja fonetyczna

a) niemiecko-słoweńska

Recenják $\leftarrow$ Krebzenbach (1286 Crebzenpach, 1502 Rakkonigk) (< psł. *rakъ);

b) słoweńsko-niemiecka

Činžat $\leftarrow$ *Senožet (1289 Wisen, 1618-1627 zue Wisen oder Zinset) $(<$ psł. *sěnožętb 'sianożęć') (Štrekelj 1906: 48);

c) interdialektalna

Borovníca $\leftarrow$ *Bravnica (brav 'bydło') (1312 Vraunyz, 1689 Brauniza, 1744 Barounize) (< brav 'drobna rogacizna', psł. *borvb, por. pol. top. Browiniec (Torkar 2017: 332). Dotychczas nazwę tę wywodzono bezwyjątkowo od ap. bor 'sosna'. 
Nikt nie zwrócił uwagi na liczne zapisy historyczne, które przemawiają za pochodzeniem nazwy od ap. brav. W gwarze Borovnicy używa się formy Bruníca, zaś w sąsiednich dialektach Vrhniki i innych osad - Barauníca (wywiad terenowy). Wymowa ta w XIX w. przyczyniła się do błędnej standaryzacji toponimu.

\section{Zniemczenie fonetyczne}

Kótlje $\longleftarrow *$ Hotlje $(1242$ Chotlach $)(<$ n. os. *Hotzlb), por. pol. top. Chotel i top. Köttlach w Dolnej Austrii (Sušnik 1968: 45, Torkar 2008: 105).

Kotmára vas $\leftarrow *$ Hotmirja ves $(1147$ Chotmarsdorf) $(<\mathrm{n}$. os. *Hotěmirz) (Kavčič 1895: 4).

\section{Przegłos}

Iméno $\longleftarrow$ *Jamljane (1404 Stadlern, 1780 Jamlanska Wesz) (n. mieszk. na -jane $<$ *jama 'dół do przechowywania plonów' (Torkar 2016a: 98). F. Bezlaj (1976: 210) wywodził top. Iméno z psł. ap. *ojbmins ‘wojownik’. Zapis z XVIII w. umożliwił — moim zdaniem — ustalenie poprawnej etymologii.

Írje $\leftarrow *$ Jurje (1436 i 1458 zu Geyring, 1780 Jerje) (<n. os. Jurij). F. Bezlaj (1976: 212) wywodził Irje od ap. ir 'wir, głębia', nie zwracając uwagi na dostępne już wówczas zapisy historyczne, umożliwiające inne objaśnienia nazwy.

\section{WNIOSKI}

W procesie ustalania etymologii nazw własnych wielką rolę odgrywa nie tylko analiza fonetyczna i semantyczna, lecz także analiza słowotwórcza, ustalenie modelu, według którego nazwa została utworzona. Okazuje się, iż w kształtowaniu się słoweńskich nazw geograficznych ważną rolę odgrywały wariacje sufiksów ekwiwalentnych. $\mathrm{Z}$ powodu licznych innowacji w rozwoju fonetycznym języka słoweńskiego wielkie znaczenie dla ustalania etymologii nazw geograficznych mają zapisy historyczne. Ponadto należy brać pod uwagę gwarowe formy nazw, a także derywaty przymiotnikowe i nazwy mieszkańców.

Dzięki dokładnej analizie materiału onomastycznego udało się znaleźć wiele nowych przykładów paralel nazewniczych do toponimów słoweńskich w innych językach słowiańskich. Po raz kolejny okazało się, iż rozwój językowy charakteryzują zarówno systemowość i przewidywalność lingwistyczna, jak i językowa niesystemowość, i wynikająca z niej nieprzewidywalność lingwistyczna (Furlan 2016: 145). 


\section{LITERATURA}

Bańkowski A. 1982: Zmiany morfemiczne w toponimii polskiej, Ossolineum, Wrocław.

Bezlaj F. 1956-1961: Slovenska vodna imena, 1-2, „Dela razreda za filološke in literarne vede” 9, SAZU, Ljubljana.

Bezlaj F. 1976: Etimološki slovar slovenskega jezika, 1. knjiga: A-J, Mladinska knjiga, Ljubljana.

Bezlaj F. 1977: O imenih Sneberje, Sostro in drugo, ,Jezik in slovstvo” 23/8, s. 225-227. [Przedruk:

M. Furlan (red.), Zbrani jezikoslovni spisi I, Založba ZRC, Ljubljana 2003, 572-574].

Bezlaj F. 1995: Etimološki slovar slovenskega jezika, 3. knjiga: P-S, dopolnila in uredila M. Snoj in M. Furlan, Mladinska knjiga, Ljubljana.

Blaznik P. 1986-1989: Slovenska Štajerska in jugoslovanski del Koroške do leta 1500, 1-3, „Historična topografija Slovenije" II, Obzorja, Maribor.

Čop D. 2007: Imenoslovje in etimologija imen, „Jezikoslovni zapiski” 13/1-2: Merkujev zbornik, s. $117-125$.

Frau G. 1978: Dizionario toponomastico del Friuli-Venezia Giulia, Istituto per l'Enciclopedia del Friuli Venezia Giulia, Udine.

Furlan M. 2016: Slovanska etimologija med jezikoslovno predvidljivostjo in nepredvidljivostjo, [w:] taż, Prispevki k slovenski in slovanski etimologiji, Založba ZRC, Ljubljana, s. 135-145.

Jožefinski zemljevidi 1995-2001: Slovenija na vojaškem zemljevidu 1763-1787 (1804): Opisi, I-VII, ZRC SAZU in Arhiv Republike Slovenije, Ljubljana.

Kavčič F. 1895: Slovenska osebna imena koroških plemičev do l. 1500, „Izvestja Muzejskega društva za Kranjsko" V/1, s. 1-7.

Kos M. 1975: Gradivo za historično topografijo Slovenije (za Kranjsko do leta 1500), 1-3, SAZU, Ljubljana; https://topografija.zrc-sazu.si.

Košmrlj M. 1970: Dvočlenska antroponima v slovenskih krajevnih imenih, „Onomastica jugoslavica” 2, s. $102-117$.

Kranzmayer E., Lessiak P. 1983: Wörterbuch der deutschen Sprachinselmundart von Zarz/Sorica und Deutschrut/Rut in Jugoslawien, Verl. des Geschichtvereines für Kärnten, Klagenfurt.

Malec M. 2003: Stownik etymologiczny nazw geograficznych Polski, PWN, Warszawa.

Pintar L. 1912: O krajnih imenih IV, „Ljubljanski zvon” 32/10, s. 550-554.

Ramovš F. 1924: Historična gramatika slovenskega jezika, II: Konzonantizem, Učiteljska tiskarna, Ljubljana.

Scheinig J. 1905: Die Ortsnamen des Gerichtsbezirkes Ferlach [Sonderabdruck aus dem 56. Programme des Staats-Obergymnasiums, Klagenfurt].

Šilov A. L. 2009: Zvenigorod: čto zvenit i zvenit li?, „Russkaâ reč”” 1, s. 93-100.

SKI 1985: F. Jakopin, T. Korošec, T. Logar, J. Rigler, R. Savnik, S. Suhadolnik. Slovenska krajevna imena, Cankarjeva založba, Ljubljana.

Skok P. 1973: Etimologijski rječnik hrvatskoga ili srpskoga jezika, 3. knjiga: poni-Ž, Jugoslavenska akademija znanosti i umjetnosti, Zagreb.

Snoj M. 2009: Etimološki slovar slovenskih zemljepisnih imen, Modrijan-Založba ZRC, Ljubljana.

Štrekelj K. 1906: Razlaga nekterih krajevnih imen po slovenskem Štajerju, 1, „Časopis za zgodovino in narodopisje" 3, s. 41-64.

Sušnik F. 1968: In kaj so ljudje ko lesovi. Koroški zapisi. Obzorja: Maribor; http://www.koropedija.si/ index.php/In_kaj_so_ljudje_ko_lesovi (dostęp 19 XII 2016).

Torkar S. 2003: K nastanku in pomenu nekaterih zemljepisnih imen v Baški dolini (Baška grapa, Hudajužna, Porezen, Loje, Logaršče, Kojca, Obloke, Robje, Podmelec), ,Slavistična revija” 51/4, s. $429-442$.

Torkar S. 2007a: O neprepoznanih ali napačno prepoznanih slovanskih antroponimih v slovenskih zemljepisnih imenih: Čadrg, Litija, Trebija, Ljubija, Ljubljana, Biljana, „Folia onomastica Croatica” 16, s. 257-273. 
Torkar S. 2007b: Substrat, adstrat ali neprepoznana slovanska dediščina? Ig-Krim-Bača, [w:] Slov'âns 'ka filologiâ: Zbirnik naukovih prac', Ruta, Černivci, s. 250-258.

Torkar S. 2008: Slovenska zemljepisna imena, nastala iz slovanskih antroponimov, „Slavistična revija” 56: Kongresna številka, s. 17-29.

Torkar S. 2009a: Flektivna derivacija v slovenskih krajevnih imenih (jezikovnozgodovinski vidik), „Slavistična revija” 56/57: Trubarjeva številka, s. 411-419.

Torkar S. 2009b: Mrvice iz imenoslovne malhe, „Traditiones” 38/1, s. 77-87.

Torkar S. 2009c: Krajevna imena v občinah Postojna in Pivka, [w:] J. Fikfak (red.), Postojna: upravno in gospodarsko središče, Galerija 2, Postojna, s. 383-405.

Torkar S. 2010a: Tvorba slovenskih zemljepisnih imen iz slovanskih antroponimov: identifikacija, rekonstrukcija in standardizacija, doktorska disertacija, Univerza v Ljubljani, Ljubljana (maszynopis).

Torkar S. 2010b: Imenoslovni vozli: Miren, Čepovan, Rubije, „Goriški letnik” 33-34, s. 821-831.

Torkar S. 2011: Rebusi v slovenski onomastiki, „Slavica Tartuensia” IX: Lingvokul turnoe prostranstvo sovremennoj Evropy čerez prizmu malyh i bol'ših âzykov, s. 353-362.

Torkar S. 2012a: Predoslje a Prelosno (po 45 letech), „Acta onomastica” LIII, s. 316-322.

Torkar S. 2012b: Variantnost'suffiksov v slovenskoj toponimii, [w:] E. L. Berezovič (red.), Ėtnolingvistika. Onomastika. Ėtimologiâ, č. 1, Izdatel'stvo Ural'skogo universiteta, Ekaterinburg, s. 147-148.

Torkar S. 2012c: Razpoznavanje slovenskih zemljepisnih imen, „Slavistična revija” 60/4, s. 693-707 .

Torkar S. 2013: Dvočlenski slovanski antroponimi v slovenski toponimiji, „Jezikoslovni zapiski” 19/1, s. $111-128$.

Torkar S. 2014: Odstiranje slovenskih krajevnih imen: Mengore in Kupljenik, „Glasnik Slovenskega etnološkega društva" 4, s. 114-115.

Torkar S. 2015a: Varianty form s perehodom $\mathrm{v}>\mathrm{g} i \mathrm{~b}>\mathrm{g} v$ slovenskoj toponimii, [w:] E. L. Berezovič (red.), Ėtnolingvistika. Onomastika. Ėtimologiâ, Izdatel'stvo Ural'skogo universiteta, Ekaterinburg, s. 279-282.

Torkar S. 2015b: Odstiranje slovenskih krajevnih imen: Sneberje in Golavabuka, „Glasnik Slovenskega etnološkega društva" 3-4, s. 108-110.

Torkar S. 2015c: Nemško-slovenski stiki v slovenski toponimiji, „Linguistica” LV, s. 161-171.

Torkar S. 2016a: Odstiranje slovenskih krajevnih imen: Gorjansko in Imeno, „Glasnik Slovenskega etnološkega društva" 1-2, s. 97-100.

Torkar S. 2016b: Krajevni imeni Davča in Avče. Substrat (keltski, romanski), adstrat (furlanski), superstrat (nemški) ali slovanska dediščina?, [w:] M. Biolik i in. (red.), Slavica. Onomastica. Regionalia. Prace dedykowane Panu Profesorowi Jerzemu Dumie, Wyd. UWM w Olsztynie, Olsztyn, s. 205-212 .

Torkar S. (2017): Razpoznavanje slovenskih zemljepisnih imen (2), „Jezikoslovni zapiski” 23/2, s. 331-341 .

Zdovc P. 1993: Slovenska krajevna imena na avstrijskem Koroškem./Die slowenischenOrtsnamen in Kärnten/: pisava, izgovarjava in naglas, vezava in sklanjatev ter izpeljava slovenskih koroških krajevnih imen, gradivo zbral, izbral in uredil P. Zdovc, Dunaj, Slovenski znanstveni inštitut, Celovec. 


\section{SKRÓTY}

$\begin{array}{ll}\text { ap. } & \text { - apelatyw } \\ \text { czas. } & \text { - czasownik } \\ \text { czes. } & \text { - czeski } \\ \text { dial. } & \text { - dialektalny } \\ \text { dop. } & \text { - dopełniacz } \\ \text { hydr. } & \text { - hydronim } \\ \text { lm. } & \text { - liczba mnoga } \\ \text { łac. } & \text { - taciński } \\ \text { mian. } & \text { - mianownik } \\ \text { niem. } & \text { - niemiecki } \\ \text { n. mieszk. } & \text { - nazwa mieszkańców }\end{array}$

$$
\begin{aligned}
& \text { n. os. } \quad \text { - nazwa osobowa } \\
& \text { oron. } \quad \text { - oronim } \\
& \text { pol. } \quad \text { - polski } \\
& \text { psł. } \quad \text { - prasłowiański } \\
& \text { serb. } \quad \text { - serbski } \\
& \text { stp. } \quad \text { - staropolski } \\
& \text { suf. - sufiks } \\
& \text { top. - toponim } \\
& \text { ukr. - ukraiński } \\
& \text { wł. - włoski }
\end{aligned}
$$

\section{ON THE MOST CHARACTERISTIC MORPHEMIC AND PHONOLOGICAL/PHONETIC CHANGES IN SLOVENIAN TOPONYMS}

\section{SUMMARY}

In proper name etymology the word-formation analysis, i.e. identifying the model used to form the name, is of particular importance, alongside the phonological and semantic aspects. The paper shows that the competition between equivalent affixes played an important role in the formation of Slovenian toponyms.

Due to numerous innovations in the phonological/phonetic development of the Slovenian language, historical records importantly contribute to the etymological analysis of toponyms, as do extant vernacular forms of the name together with their adjectival and demonymic derivations.

As expected, finding the counterparts in other Slavic languages — or confirming their non-existence — often proved very useful when analysing Slovenian toponyms.

Likewise, the present study once more shows that linguistic development is characterized by both linguistic systematicity and therefore linguistic predictability, and also linguistic non-systematicity and therefore linguistic unpredictability (Furlan 2016: 145).

Key w ord s: morphemic changes, phonological/phonetic changes, Slovenian toponyms, etymology of Slovenian geographical names 